Mschr. Geburtsh. 1943;115:1

\title{
Herrn Prof. Dr. Ernst anderes zum 60. Geburtstag
}

\section{Sehr geehrter Herr Professor!}

Zu Ihrem 60. Geburtstag hätten wir Ihnen von der «Monatsschrift» gerne einen Festband gewidmet mit Beiträgen Ihrer Freunde und Schüler, sowie der Herausgeber und Mitarbeiter der «Monatsschrift». Die Ungunst der Zeiten bildetleider ein unüberbrückbares Hindernis. Wennsich trotzdem einige Assistenten der Frauenklinik von Zurich und Basel zusammengefunden haben, um Ihnen ihre Ar-beiten zu widmen, so soil das ein Zeichen des freundschaft-lichen Gedenkens auch im Namen aller derer sein, die nicht erreichbar waren.

Nachdem Sie sich kurz vor Ausbruch des Krieges ent-schlossen hatten, die Leitung der «Monatsschrift» zu über-nehmen und die alte Tradition nicht nur fortzuführen, sondern die Basis zu verbreitern, konnten Sie aus den Zu-sagen der Mitarbeiter aus vielen Ländern schon ersehen, daß Sie sich den Dank der Gynaekologen für diese Auf-gabe erwerben würden. Niemand kann daran zweifeln, daß Sie nach Wiederherstellung der internationalen Ver-bindungen die wissenschaftliche Zusammenarbeit so noch weiter fördern werden.

Wir hoffen und wünschen, daß es Ihnen noch recht lange gegeben sein möge, Ihre fruchtbringendeTätigkeit für die Wissenschaft, Ihre Schüler und die Kranken auszuüben.

Die Oberärzte der Für die Redaktion: Th. Koller Universitätsfrauenklinik Zurich

H. J. Wespi und H. Winzeler Verlagsbuchhandlung S. Karger 